\title{
Gorilla Census
}

\section{A. H. Harcourt and A. F. G. Groom}

The authors spent three months in the Virunga volcanoes, in Rwanda, making a census of mountain gorilla groups as an aid to Dian Fossey's long-term studies of this highly endangered primate. The FPS assisted this census with a grant from the Oryx $100 \%$ Fund.

'It has been my fortune to be the first white man who can speak of the gorilla from personal knowledge ... and ... I can vouch that no description can exceed the horror of its appearance, the ferocity of its attack, or the impish malignity of its nature.' Paul du Chaillu's description written more than a hundred years ago would be discounted today as exaggerated and highly over-coloured, but it is only in comparatively recent years, since the late fifties, that there have been any scientifically acceptable attempts to study the gorilla in its natural environment. Early workers in this field include Donisthorpe, Osborne, Kawai, Mizuhara, Emlen and Schaller, who studied its distribution, morphology, and ecology. In particular, for the past five years, Dian Fossey, sponsored and supported by the National Geographic Society, has been studying the behaviour of the mountain gorilla Gorilla gorilla beringei in the Parc des Volcans, which includes the greater part of the Virunga volcanoes and is divided by the Zaire (Congo)-Rwanda border.

A detailed behaviour study of the gorilla is of the greatest importance, quite apart from its intrinsic value and interest, for an understanding of the animal's needs and how to conserve it. But the problems involved force the worker to restrict his study to the limited number of animals that are more or less continuously accessible on foot from a semi-permanent camp. Even within large areas of the Parc des Volcans very little is known about the numbers and distribution of the gorilla population, let alone in other areas within its reported range. The numerous estimates amount to guesses based on extrapolation from the known numbers in very small areas. Thus, Schaller estimated that the whole eastern gorilla population in 1959 was between 5000 and 15,000 , of which $400-500$ were in the Virunga region. Miss Fossey's current estimate for the Virunga region is $375-400$ animals. The eastern population of gorilla, whose reported range is shown on map I, is generally recognized as being morphologically distinct from the lowland gorilla G. g. gorilla; but Groves makes a further distinction, also on morphological grounds, and divides the eastern population into two subspecies: G. g. beringei occupying the Virunga region and a small area to the west of Lake Kivu known as the Mount Kahuzi region, and $G$. g. graueri, occupying the rest of the range shown. There would, therefore seem to be fewer than 1000 G. g. beringei left, and much the larger part of the rest of the eastern range is outside the National Park boundaries.

The precarious position of the sub species emphasises the need for further information. There is little doubt that the mountain gorilla is threatened with extinction (and for present purposes mountain gorilla 


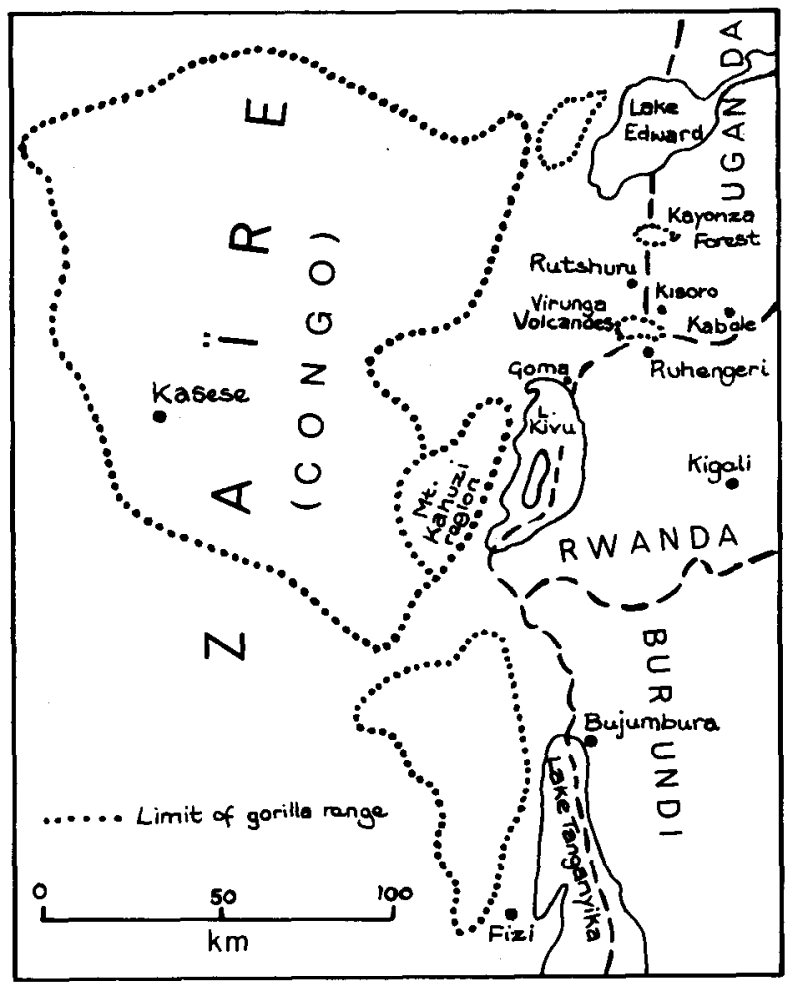

includes both beringei and graueri). In the absence of adequate conservation measures, or more vigorous prosecution of those already taken, it would not be unduly alarmist to estimate that the gorilla will have disappeared from the Virunga region in less than twenty-five years, even though most of this area is described as a national park. There is no reason to suppose that other areas in the mountain gorilla's already fragmented range are any less vulnerable.

Ideally, conservation measures should be based on an accurate knowledge of changes in numbers and distribution in response to different pressures over an extended period of time. Detailed knowledge is necessary, not least to convince the governments concerned, continually harassed as they are by the political imperatives of underdevelopment and of the urgency of the situation. Previously, action taken without accurate information has been potentially catastrophic to the cause of conservation. A case in point was the Rwanda Government's appropriation of large areas of the Parc des Volcans. In 1958, land was taken for cattle grazing, and recently another large area was taken for a pyrethrum project, a total of 10,000 hectares in all. The land was taken in strips pushing the park boundary to the very base of the volcanoes. If any thought was given to the question of intrusion into the gorillas' habitat, it was assumed that they lived only on the mountains and would be unaffected. However, apart from this wrong assumption and given that only unacceptably harsh measures can prevent incursions into the park by the local 


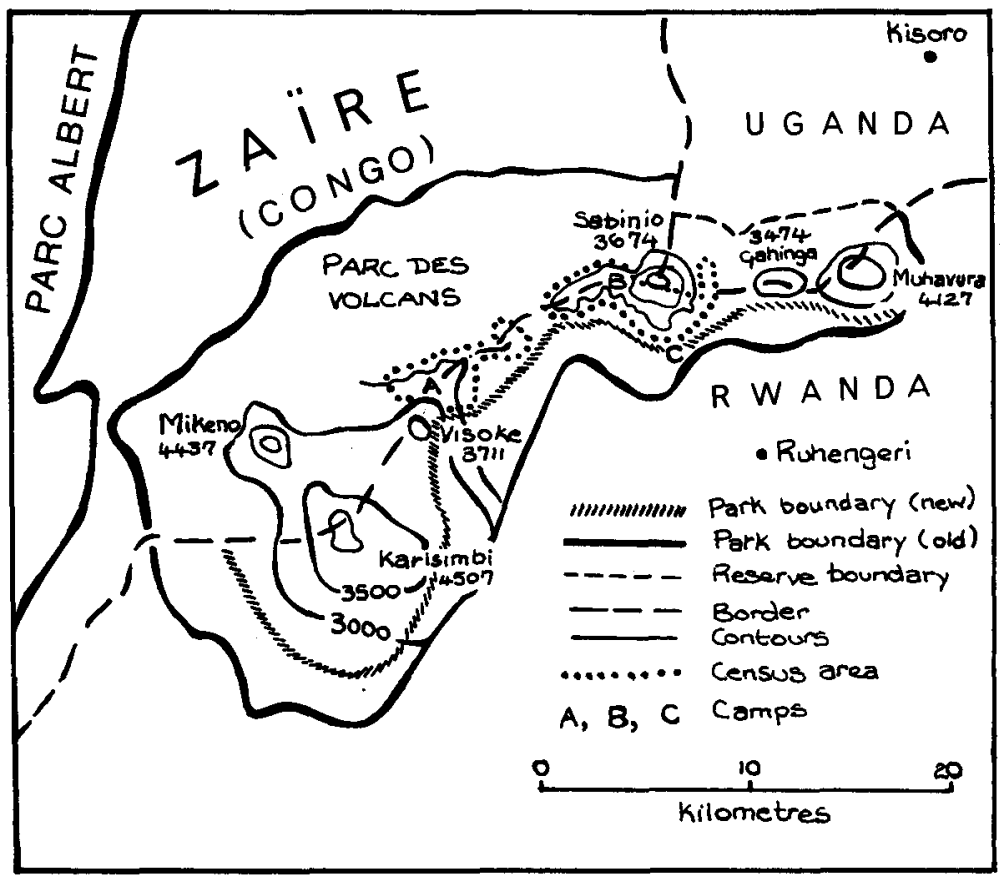

population, it is now apparent that an invaluable buffer zone has been lost, quite apart from the severe restriction imposed on other species, notably elephants.

Appreciating the urgent need for more information, the National Geographic Society made money available to support census workers operating under the direction and supervision of Miss Fossey. The project first really got under way early in 1971 and it was to continue the work that the authors, again supported by the National Geographic Society and greatly assisted by the Fauna Preservation Society, went to the Parc des Volcans in the summer of the same year. Map 2 shows the area covered by our part of the work and the positions of the camp-sites. Harcourt arrived in late June and after a ten-day introduction to some of the problems from Miss Fossey, established his first census camp at Ngezi Lake. Groom arrived in early August by which time the second camp had been set up at Muside. For the last three weeks of September, camp was moved for the last time to Kabgende.

The aim of this short summer period was to search both Sabinio, a hitherto neglected mountain and one easily pinpointed since Zaire, Uganda and Rwanda borders meet at its summit, and the extensive saddle area, including several small craters between Visoke and Sabinio. The technique was straightforward. Each day predetermined areas were searched as thoroughly as the vegetation and terrain would allow. All gorilla sign, both old and new, was noted and trails, where possible, followed. Even an old trail, if it was still clear, was worth following, not in the expectation of immediately locating the animals that left it, but in order to gather information about the size and composition of the group from night-nest counts and also information about plant 

ON MT VISOKE

Right

A young male

Below

An aggressive big silverback male

Left
Part of a group of $\mathbf{2 0}$ gorillas including the big silverback

A. H. Harcourt
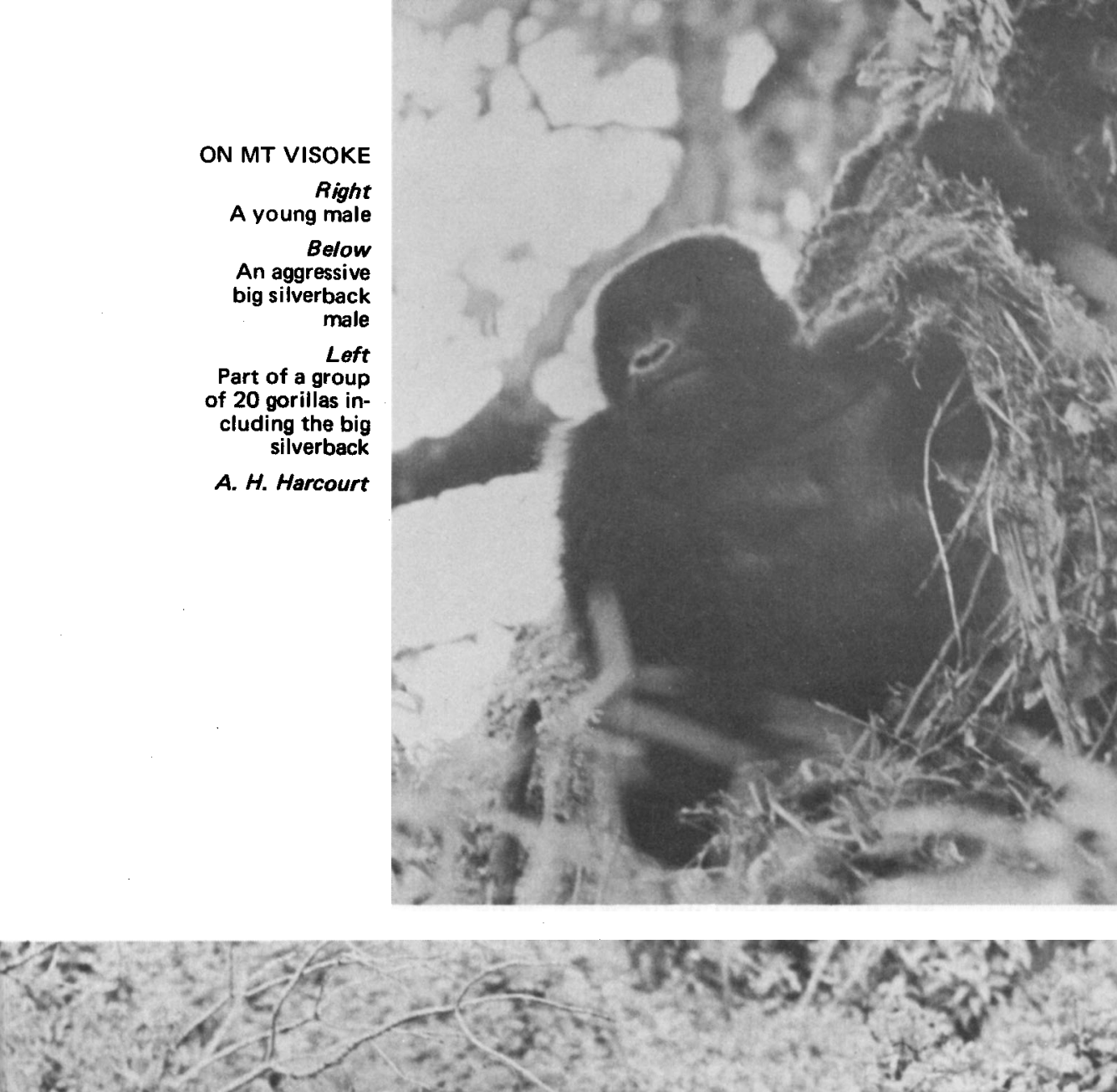

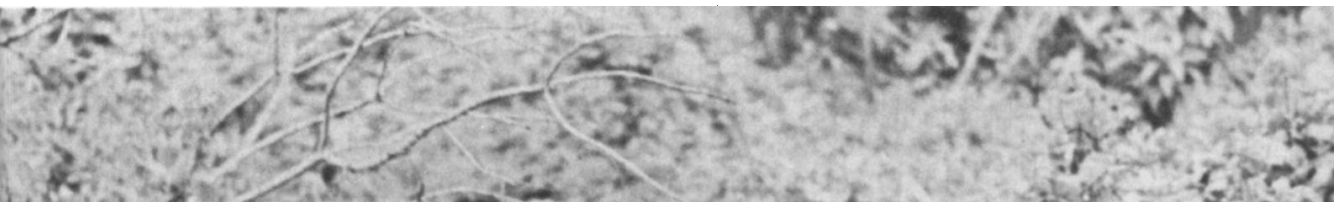

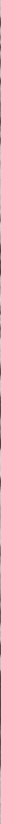

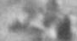




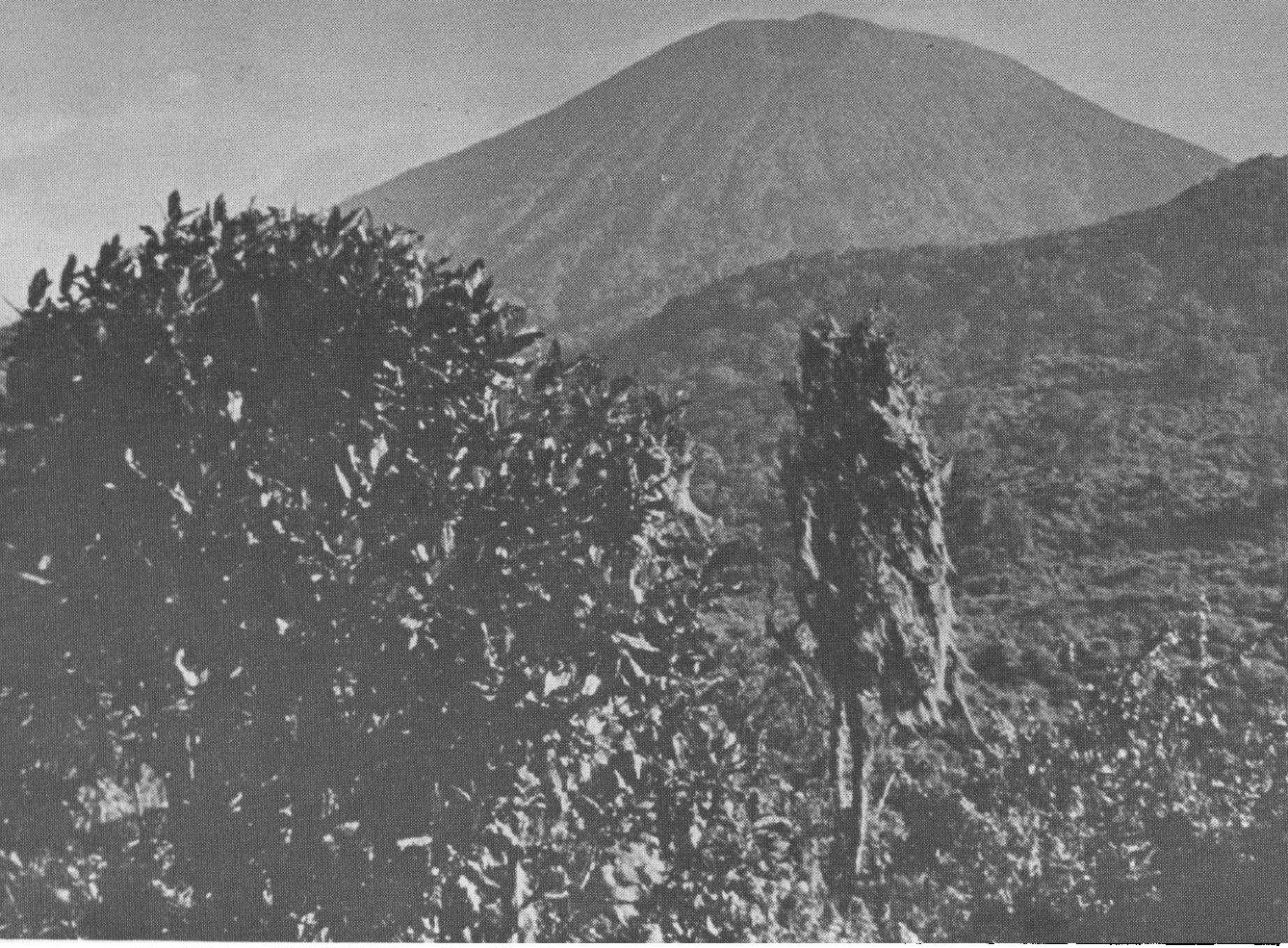

GORILLA COUNTRY - Mt. Visoke

tracking very difficult to an untrained eye, but, much more often, the problem was the very thick ground cover of low and medium height plants. In such areas, nothing could be seen further than a few yards, any progress was difficult and unobtrusive progress almost impossible. In consequence, it was a rare occasion that the gorilla could be watched unaware of the observer's presence.

A typical contact was therefore preceded by a period of tracking. The first indication of the immediate proximity of the group would usually be a strong smell, apparently emitted only by silver-backed males and only then under conditions of excitement or stress. As all activity would have ceased as the observer approached, the first noise to be heard would probably be a vocalisation, either an alarm bark or, perhaps, a scream or roar if the animals felt particularly threatened. It was then essential to calm the gorilla's fears sufficiently to arouse their natural curiosity, so the observer would stay still and make soft reassuring sounds such as whimpers, grunts, belches and feeding noises. If he felt he was being watched, he might 'groom' himself and make feeding gestures as well as noises. Perhaps he might hoot and chest-beat softly.

This behaviour would normally elicit a response in the form of chest-beats or some vocalistion, usually from a silver-backed male but occasionally from other group members. If maintained, and depending on the initial fear of the animals, it was normally possible to arouse sufficient curiosity for the gorilla to come and have a look. Sometimes, 
the observers could then study them through binoculars, perhaps draw a 'nose-print' and possibly photograph them, although care was needed since, for unhabituated gorillas, as well as for many other species, staring is an aggressive action and the large binocular 'eyes' could easily frighten them.

Sometimes if the situation was particularly advantageous to the gorillas, fear played no part in the encounter. Thus, on one occasion, Groom found himself being watched by a silver-backed male thirty yards away and a few feet above him. When the gorilla saw that he had been spotted, he retreated a few yards, but it was a simple matter to allay his fears, whereupon two other members of the group appeared. Once more only curious, the silver-back advanced to within about twenty-five yards and, following renewed appeasement gestures from the observer, began to feed. After an hour, it began to rain and both gorilla and observer sat huddled, immobile, watching each other - both apparently equally miserable!

Even for someone warned repeatedly against the use of such obviously anthropomorphic language, it is very hard to avoid using it when describing these encounters. Harcourt too had similar experiences when he was able to sit close to a large group of seemingly unworried animals while they foraged.

However these encounters were far from the norm. Usually the gorillas' reaction was one of fear, especially if the observer was too close or above the animals, or the contact was unexpected; on such occasions it was frequently impossible to allay their fears. Characteristically, the group would flee leaving only a strong silver-back smell and a trail marked usually with fresh dung, defaecation being part of the normal response to fright. The great variation in behaviour suggested that many had previously been frightened by contact with man.

The Rwanda side of the Parc des Volcans is threatened by the local population in various ways. Bee-keepers and wood-cutters roam this park and it was ironical, in an area of high elephant density, to see more tree damage caused by machetes than by elephants. Regeneration was very slow, the saplings being particularly vulnerable, and it would be unfortunate if the park followed the course of the rest of the country where almost all the native species have been replaced by fast-growing eucalyptus. Large herds of up to 200 cattle are driven far into the park where they churn the ground and make more forage unusable by the wildlife than they actually eat, Finally, of course, there are poachers, and different types of trap may be found in large numbers all over the park. The gorilla is not their usual target, but traps do not discriminate and there was evidence that they are occasionally caught. Sometimes, however, the sole target is undoubtedly the gorilla and the reasons are obscure. The mutilated bodies of two silver-backed males, killed by poachers, were found, with various pieces (genitals, little fingers, and a piece of the thigh) cut off. Of the explanations offered, witchcraft practices seem the most likely.

It is arguable that direct hunting of this sort and on an apparently limited scale, would not endanger the ultimate survival of the species. What is clear, however, is that the Rwandan park must be properly 
protected. The Zaire side is patrolled and guarded perhaps as much as could be expected, but the Rwandan Conservateur is greatly hampered by lack of financial support.

With no firm enforcement of the law, local incursions into the park are likely to become increasingly confident. The Virunga volcanoes form a single, extended chain. If the land between the peaks, which is suitable for cultivation, were taken from the park, under whatever pretext, it would be naive to suppose that the mountain gorilla would survive on the mountain tops alone.

However, the picture is not necessarily so dismal. There are reports that the Rwandan Conservateur is to receive more of the support he needs and there are no currently advertised plans for further appropriations of land. But Rwanda has the highest population density in Africa, and land is at a premium. A proclaimed and informed interest in the gorillas by the developed world is essential to ensure their survival. SUMMARY OF RESULTS

First Census Camp - Ngezi - 28th June to 25 July.

Total Days Field Work: 24

Total Animals Found: $25-3$ lone silver-backs;

Sub-group of:- 1 silver-back and 1 young male.

Group of:- 1 silver-back; 14 adults; 2 juveniles; 3 infants.

10 other gorillas were known to have been in the area, but they were not seen.

Second Census Camp - Muside - 25 July to 4 September.

Total Days Field Work: 54

Total Animals Found: $13-1$ lone adult.

or 19 Sub-group of:- 1 silver-back and 1 young adult.

Group of: (i) 2 silver-backs; 3 adults.

(ii) 1 silver-back; 4 adults; 1 infant.

There might have been one more group of: 6 animals -1 silver-back; 4 adults; 1 juvenile.

Third Census Camp - Kabgende - 4 September to 24 September Total Days Field Work: 33

Total Animals Found: $18-1$ lone silver-back.

or 23 Sub-group of: 1 silver-back and 1 adult.

Group of: (i) 1 silver-back; 1 adult; 1 juvenile.

(ii) 1 silver-back; 3 adults.

(iii) 1 silver-back; 4 adults; 1 juvenile, 4 infants.

There might have been one more group of: 5 animals -1 silver-back; 3 adults; 1 juvenile. 


\section{Acknowledgments}

We would like to offer our most grateful acknowledgments to the National Geographic Society and the Fauna Preservation Society for their invaluable financial support. We would also like to thank the Rwandan and Congolese Conservateurs of the Parc des Volcans for their kind permission for us to work in the park and, finally, we are deeply indebted to Miss Dian Fossey for her generosity, kindness and constant encouragement.

\section{References}

CAMPBELL, R. I. M. 1970. Mountain gorilla in Rwanda. Oryx 10: $256-7$.

DONISTHORPE, J. 1958. A pilot study of the mountain gorilla in S.W. Uganda, February-September, 1957. S.Afr.J.Sci. 54: 195-217.

Du CHAILLU, P. 1861. Explorations and Adventures in Equatorial Africa. New York.

FITTER, R, 1968, Vanishing Wild A nimals of the World. London.

FOSSEY, D. 1970. Making friends with mountain gorillas. National Geographic Magazine, 157: 48.

1971. More years with mountain gorillas. National Geographic Magazine, $140: 574$.

GROVES, C.P. 1970. Population systematics of gorilla. J.Zool., Lond. 161: 287-300.

KAWAI, M. and MIZUHARA, H. 1959. An ecological study of the wild mountain gorilla. Primates 2: 1-42.

NAPIER, J.R. and NAPIER, P.H. 1967. A Handbook of Living Primates. New York and London.

REYNOLDS, V. 1967. The Apes. London.

SCHALLER, G.B. 1963. The Mountain Gorilla - Ecology and Behaviour. Chicago and London.

Also Oryx 10: 7, 91, 143, 256 (see above), 284.

\section{IUCN and the Pet Trade}

Three conditions which should be met before any animal species is taken for the pet trade are laid down by IUCN and WWF in a recent statement. They are: that the species is sufficiently abundant in the wild to permit exploitation; that it has been proved suitable for use as pets; and that escaped individuals would present no dangers to human or animal health or to the natural surroundings. The statement of course unreservedly condemns the all-too-common taking of rare species - the South American cock-of-the-rock is a glaring example which because it is so rare commands an extremely high price that in turn intensifies the search for more.

\section{Petfoods without Whale Meat}

Following a BBC TV programme on whales, which revealed that many pet foods were made with whale meat, the World Wildlife Fund investigated to find out which makes do not use either whale or kangaroo meat. Two firms, Spillers and Wakefields (Lucky brand) are in the clear, and pet foods sold by Tesco and Marks and Spencer contain no whale meat.

\section{Oryx by Air}

Oryx can be posted to overseas members by air. For details of extra cost apply to FPS, C/o London Zoo, London NW1 4RY. 